\title{
Trait Emotional Intelligence and Mathematics Achivements among Undergraduates in Higher Learning Instituition of Sarawak.
}

\author{
GOH YI WEN \& TAN KOCK WAH* \\ Faculty of Cognitive Science \& Human Development, University Malaysia Sarawak, Kota Samarahan, \\ 94300 Sarawak, Malaysia \\ *Corresponding author: kwtan@unimas.my
}

\begin{abstract}
Emotional Intelligence appears to be a significant influencing factor in academic achievements. This study aims to identify the relationship between trait emotional intelligence and mathematics achievements (a relatively sparse research areas of academic achievements) among undergraduates in higher learning institution of Sarawak. 100 respondents from a higher-level institution of Sarawak participated in this study. Trait Emotional Intelligence Questionnaire (TEIQue) is used to measure the trait emotional intelligence of the undergraduates. The result was analysed using descriptive analysis and inferential analysis, namely two-way ANOVA and Pearson's correlation. Two-way ANOVA was used to test if there is significant difference in demographic attributes (gender and place of residence) towards maths achievements and trait emotional intelligence of the undergraduates. Pearson Correlation was used to test the relationship between trait emotional intelligence and mathematics achievements of the undergraduates. Generally, this study found that there is no significant difference for factors related to demographic attributes (gender and place of residence) against maths achievements and trait emotional intelligence of the undergraduates. Meanwhile, a relationship was found between trait emotional intelligence and mathematics achievements among undergraduates in higher learning institution in Sarawak. The outcome of the study appears to suggest that trait emotional intelligence can help undergraduates to understand themselves more and to control and manage their emotions and feelings and have better relationship with their surroundings. And this could positively impact on their maths achievements.
\end{abstract}

Keywords: trait emotional intelligence, mathematics achivements, undergraduates

Copyright: This is an open access article distributed under the terms of the CC-BY-NC-SA (Creative Commons AttributionNonCommercialShareAlike 4.0 International License) which permits unrestricted use, distribution, and reproduction in any medium, for noncommercia purposes, provided the original work of the author(s) is properly cited.

\section{INTRODUCTION}

In today's fast-paced world, students face different kinds of challenges in life especially in overcoming academic challenges (Wu, Garza, and Guzman, 2015). Academic difficulties and achievements among students are topics that receive persistent attention especially in recent years. However, society usually pays less attention to the influence of affective dimensions in helping students to cope with academic difficulties and achievement problems. According to a study in Finland, one of the important factors that caused stress and depression among students was academic performance (Essel \& Owusu, 2017), resulting in students entertaining suicidal ideations and thoughts (Pillay, 2017). Not surprisingly then, suicidal tendecies among students appeared to be on the rise (Pillay, 2017), and youth suicides apperaed to be a serious concern in many countries (Durisch, n.d.).

Mathematics anxiety among students is a common reported problem among students both in foreign and local contexts (Beilock \& Maloney, 2015; Khairiyah, Ismail \& Yusof, 2016). There were also several suicide cases over the past years seemingly related to poor performance in mathematics (Goh Yi Wen, 2018). However, research studies on factors that lead to suicidal stress and depressions among youth due to poor maths performance is relatively scarce. Cummins (2014) reasoned, in this regard, that emotional intelligence could be an important influencing factor in explaining youth suicide and thier involvement in arrays of other social problems. Hence, it was argued that emotional intelligence could perhaps be an effective intervention tool for improved maths performances and a good antidote to academic stress and difficulties leading to suicide ideations and attempts (Cha, Christine \& Marin, 2009; Aradilla-Herrero, Tomás-Sábado, \& Gómez-Benito 2013). Thus, apart from the traditional IQ, Emotional Intelligence (EI) is seen by researchers to possess the ability to explain performance outcomes (Gardner, 1983). In sum, mathematics anxiety could potentially be a factor that could cause unncessary stress and difficulties to students and hence affecting academic performance and in turn developed into anxiety or depression problems which could lead to suicidal ideations. So, it is crucial to investigate if emotional intelligence is predicitive of mathematical performances as incompetent EI, as many had argued, is likely to result in students developing anxiety and depression problems linking to suicidal ideations 
and intentions (Cha, Christine \& Marin, 2009). Because, if indeed, EI is a significant predictor of mathematical performances amongst students, then it should be emphasized more as a tool, alongside other intervention means, to improve student performance in mathematics.

\section{Problem statement \& objectives}

The importance of mathematical learning in virtually all aspects of life cannot be overemphasized (Wilkins \& Ma, 2002; Wile 2017). However, mathematical achievements among students have always been a problem. According to Festus (2012), students appeared to perform poorly in most maths examinations. Similar predicaments appear to apply in the case of Malaysia (Wahid, Yusof \& Razak, 2014). Meanwhile, Brian \& Jefferey (2012) argues that emotional self-efficacy or trait emotional intelligence appeared to reduce maths anxiety and its impact. Additionally, Mohamed \& Waheed (2011) identified three components that become central in influencing student learning attitudes and affective traits (emotions and feelings) was one of them. For the acquisition of varied skills that foster educational success, positive emotions appeared to link to educational settings (Corradino \& Fogartym, n.d.). This was supported by Espinosa (2016) which showed that trait emotional intelligence could improve students' confidence in mathematical problem solving abilities and students's attitude had positive impacts on the resulting outcomes. The findings in Espinosa (2016) were supported by Ogundokun and Adeyemo (2010), and Mavroveli and Sánchez-Ruiz (2011). Conversely, Petrides et al. (2004) had shown that trait EI or personality traits did not predict maths performance. Therefore, conflicting results of these studies demonstrate that its a worthy topic for further investigations.

Meanwhile, different domains of trait emotional intelligence could affect maths achievements in different ways (Espinosa, 2016), e.g., geographic (place of residence) and demographics characteristics (Whitfield, 2012), among others. Sindermann, Kendrick, Becker, Li, Li and Montag (2017) showed how students' primary emotional traits were shaped when they were growing up in urban compared to rural areas and this had resulted in expectations of adverse emotional effects from growing up in urban areas compared to rural areas. Exploring on gender related issues, Siegling, Saklofske, Vesely, and Nordstokke (2012) opined that male were known to score higher in the intrapersonal domains of well-being and self-control whilst their female counterparts did well in the interpersonal domains of emotionality and sociability based on the TEIQue.

According to Jiuan (2009), concerns emerged when the possible differences based on the demographic variables such as gender that could affect undergraduates' maths achievements was not of particular concern to Malaysian educators. Besides, according to Ismail and Halimah (2007), maths achievements of a student could be affected by their demographic characteristics and the characteristics mentioned and discussed the most was gender related. The study of Ismail and Halimah (2007) showed that girls attained higher maths achievement compared to boys in Malaysia. However, the study of Alkhateeb (2010), and Gallagher and Kaufman (2005) found that boys usually performed better than girls in maths. These contradictory findings points to a potential research gap that this study seeks to address. In addition, demographic characteristics in terms of place of residence is also a factor that could affect the difference in maths achievement (Ratnawati \& Ismail, 2003). According to Ratnawati and Ismail (2003), students living in the rural areas had more difficulty in achieving good results in mathematics than those living in urban areas due to their difficulty in understanding mathematics which was taught in the English language thus making it hard for students in the rural areas to achieve good results in the subject. Scant research works in this area makes it a worthwhile line of investigation topic.

\section{Research Hypothesis}

\begin{tabular}{lcl}
\hline Test Performed & Null Hypothesis \\
\hline Two-way ANOVA & $\mathrm{H}_{0} 1$ & $\begin{array}{l}\text { There is no significant difference in maths performance in terms of } \\
\text { undergraduates' demographic attributes (gender and place of residence) } \\
\text { There is no significant difference in trait emotional intelligence in terms of } \\
\text { undergraduates' demographic attributes (gender and place of residence). } \\
\text { There is no significant relationship between trait emotional intelligence and } \\
\text { maths performance among undergraduates. }\end{array}$ \\
$\begin{array}{l}\text { Pearson's Product } \\
\begin{array}{l}\text { Moment } \\
\text { Correlation (r) Test }\end{array}\end{array}$ & $\mathrm{H}_{0} 3{ }^{2}$ & \\
\hline
\end{tabular}




\section{MATERIALS \& METHODS}

Data for the study was collected from the Faculty of Business Administration, UNIMAS. The population in this research were the undergraduates of higher learning institution in Sarawak. In this research, simple random sampling will be used with a sample size of 100. Quantitative method is used for data collection in this research. Hence, a set of questionnaires (TEIQue) was distributed to the sample selected. Trait Emotional Intelligence Questionnaire (TEIQue) was obtained from the London Psychometric Lab based in University College London (Petrides, 2009). It is one of the world's best-researched and most widely applied psychometric instruments. There were two parts in the questionnaire in which Part A contained demographical information such as gender, place of residence and maths grades; Part B contained questionnaires related to trait emotional intelligence and was analysed using Trait Emotional Intelligence Questionnaire-Short Form (TEIQue-SF) with 7 point LikertScale. Basically the study aims to determine if undergraduate demographic attributes (Gender and place of residence) influence their maths performance; to find out if undergraduate demographic attributes (gender and place of residence) influnce trait emotional intelligence and to investigate the relationship between trait emotional intelligence and maths performance of the undergraduates.

Two variables were used in this research, in which the independent variables were the demographic attributes (gender and place of residence) and maths achievements and trait emotional intelligence (using TEIQue-SF) been the dependent variables. In this research, the pilot test was performed using 30 samples and the instrument was found to be reliable (Cronbach Alpha 0.828). The questionnaire was also validated (Siegling, Vesely, Petrides, and Saklofske, 2015).

\section{RESULTS AND DISCUSSIONS}

$\mathrm{H}_{0}$ 1: There is no significant difference in maths performance in terms of undergraduates' demographic attributes (gender and place of residence)

Table 1. Descriptive statistics of gender and place of residence (math performance).

\begin{tabular}{|c|c|c|c|c|c|c|}
\hline \multirow[t]{3}{*}{ Gender } & \multicolumn{6}{|c|}{ Place of residence } \\
\hline & \multicolumn{3}{|c|}{ Urban } & \multicolumn{3}{|c|}{ Rural } \\
\hline & $\mathrm{N}$ & $\mathrm{M}$ & SD & $\mathrm{N}$ & $\mathrm{M}$ & SD \\
\hline Male & 18 & 3.2 & 0.84 & 14 & 3.29 & 0.72 \\
\hline Female & 41 & 3.5 & 0.74 & 27 & 3.77 & 0.37 \\
\hline
\end{tabular}

Table 2. A Two-Way ANOVA test for between-subject effects (gender and place of residence on maths performance).

\begin{tabular}{llllll}
\hline Source & $\begin{array}{l}\text { Type III Sum of } \\
\text { Squares }\end{array}$ & df & $\begin{array}{l}\text { Mean } \\
\text { Square }\end{array}$ & F & Sig. \\
\hline Corrected Model & $4.121^{\mathrm{a}}$ & 3 & 1.374 & 2.996 & .035 \\
Intercept & 1004.968 & 1 & 1004.968 & 2191.562 & .000 \\
Gender & 3.229 & 1 & 3.229 & 7.043 & $\mathbf{. 0 0 9}$ \\
Place of Residence & .627 & 1 & .627 & 1.367 & $\mathbf{. 2 4 5}$ \\
Gender * Place of Residence & .174 & 1 & .174 & .380 & $\mathbf{. 5 3 9}$ \\
Error & 44.022 & 96 & .459 & & \\
Total & 1266.363 & 100 & & & \\
\hline Corrected Total & $\mathbf{4 8 . 1 4 3}$ & $\mathbf{9 9}$ & & & \\
\hline
\end{tabular}

Table 1 shows the difference between Male who lived in Rural areas ( $n=14, M=3.286, S D=0$. 727$)$, Male who lived in Urban areas $(\mathrm{n}=18, \mathrm{M}=3.2044, \mathrm{SD}=0.842)$, Female who lived in Rural areas $(\mathrm{n}=27, \mathrm{M}=3.766$, $\mathrm{SD}=0.367)$, and Female who lived in Urban areas $(\mathrm{n}=41, \mathrm{M}=3.5039, \mathrm{SD}=0.735)$ in maths performances (grades). Table 2 shows the outcomes of the test comparing demographic attributes of subjects on maths performance in a 
two-way ANOVA analysis in which $F(1,96)=7.043$. Gender $(p=0.009)$ was found to be significant while place of residence $(p=0.245)$ and interaction between gender*place of residence $(p=0.539)$ were not significant. Therefore, the null hypothesis for place of residence and interaction between gender*place of residence could not be rejected. Thus, there was no significant difference in terms of students' demographic attributes (place of residence) and (gender*place of residence) on maths performance. However, gender was found to be a significant influencing factor in maths performances.

Contrary to the finding of this study in which female was found to be generally performing better than male (Table 1), Gallagher and Kaufman (2005) found that male was inclined to perform better than female in maths. Reason given for male scoring better than female in maths achievements was because male tended to have higher confidence in their mathematical abilities compared to female (Gallagher and Kaufman, 2005), and correspondingly, female reportedly had lower self-confidence in mathematics (Moakler, Kim, \& Minsun, 2014; Stankoy, Lee, Luo \& Hogan, 2012). Moreover, it was argued that male had special edge in spatial skills and appeared to perform better in mentally representing and manipulating objects in space (Gallagher and Kaufman, 2005), skills crucial for the mastery of mathematics. Besides, females might have hindered their maths performance on the examination day because they tended to dwell lengthily on problems and wasted time unnecessarily in answering questions (Gallagher and Kaufman, 2005). However, the result of this study was supported by Ismail and Halimah (2008), and Alkhateeb (2010) which reported that gender could be a significant influence on students' maths performances. In particular, this study finds that female generally scored better than male. This appears to corroborate the findings of Ismail and Halimah (2008), and Alkhateeb (2010) which reported that female appeared to score better than male because apparently female enjoyed more than male in learning mathematics.

Meanwhile, the two-way ANOVA analysis shows that place of residence has no significant influence on maths performances as well as in the interaction between gender and place of residence. This result contradicted the study of Bértola, Prados, and Williamson (2010) in which it was claimed that those living in the rural areas had higher levels of heterogeneity as those living there were mostly poverty stricken. Further, Ratnawati and Ismail (2003) claimed that those living in the rural areas had more difficulty in achieving good results in mathematics than those living in urban areas due in part to language barrier as mathematics was taught in the English language. However, contrary to the above, the finding of the present study in which no significant difference is found in place of residence vis-à-vis mathematics results is explicable owing to government efforts in narrowing the imbalances between urban and rural schools (in terms of resources and facilities) and exposures to television and Internet in the rural environment had assisted students in rural areas to study English so they could keep up with their maths which was taught in the English language. This was supported by the study of Alokan \& Arijesuyo (2013). In sum, the outcomes of the present study suggest that the null hypothesis failed to be rejected. And this was supported by the few known studies discussed in the aforementioned.

\section{$\mathbf{H}_{0}$ 2: There is no significant difference in terms of undergraduates' demographic attributes (gender and place of residence) on undergraduates' trait emotional intelligence.}

Table 3 shows the difference between Male who lived in Rural areas ( $\mathrm{n}=14, \mathrm{M}=117.5, \mathrm{SD}=13.1778)$, Male who lived in Urban areas $(n=18, M=123.389, S D=21.536)$, Female who lived in Rural areas $(n=27, M=120.812, S D$ $=18.330)$, and Female who lived in Urban areas $(n=41, M=119.683, \mathrm{SD}=15.090)$ in trait emotional intelligence. Meanwhile Table 4 shows the result of the tests in demographic attributes of subjects on trait emotional intelligence in a two-way ANOVA analysis in which $\mathrm{F}(1,96)=0.136$. Gender $(\mathrm{p}=0.713)$ and place of residence $(p=0.790)$ and both gender*place of residence $(p=0.151)$ were all insignificant and hence the null hypothesis could be rejected. Thus, there was no significant difference in terms of undergraduates' demographic attributes (gender and place of residence) in relation to trait emotional intelligence.

Table 3. Descriptive statistics for trait emotional intelligence according to gender and place of residence.

\begin{tabular}{|c|c|c|c|c|c|c|}
\hline \multirow[t]{3}{*}{ Gender } & \multicolumn{6}{|c|}{ Place of Residence } \\
\hline & \multicolumn{3}{|c|}{ Urban } & \multicolumn{3}{|c|}{ Rural } \\
\hline & $\mathrm{N}$ & $\mathrm{M}$ & SD & $\mathrm{N}$ & $\mathrm{M}$ & SD \\
\hline Male & 18 & 123.39 & 21.53 & 14 & 117.5 & 13.18 \\
\hline Female & 41 & 119.68 & 15.09 & 27 & 120.81 & 0.37 \\
\hline
\end{tabular}


Table 4. A two-way ANOVA test of between-subject effects (gender and place of residence on trait emotional intelligence).

\begin{tabular}{lrrrrr}
\hline Source & \multicolumn{1}{c}{$\begin{array}{c}\text { Sum of } \\
\text { Squares }\end{array}$} & df & Mean Square & F & Sig. \\
\hline Corrected Model & $546.199^{\mathrm{a}}$ & 3 & 182.066 & .728 & .538 \\
Intercept & 1244928.080 & 1 & 1244928.080 & 4976.842 & .000 \\
Gender & 34.101 & 1 & 34.101 & .136 & .713 \\
PlaceofResidence & 17.795 & 1 & 17.795 & .071 & .790 \\
Gender* PlaceofResidence & 525.111 & 1 & 525.111 & 2.099 & .151 \\
Error & 24013.841 & 96 & 250.144 & & \\
Total & 1492050.000 & 100 & & & \\
\hline Corrected Total & $\mathbf{2 4 5 6 0 . 0 4 0}$ & $\mathbf{9 9}$ & & &
\end{tabular}

This was supported by Siegling, Furnham and Petrides (2015) which argued that gender was not an influence on trait emotional intelligence as the study showed that both the male and female TEIQue scores were almost similar and there was no gender influences on the scores. However, this result was contradicted by the study of Guastello and Guastello (2003) where it was found that gender had social traits that may impact favourably on the TEIQue scores, e.g., traits of assertiveness were more common among the male and empathy which was more prominent in female. Corresponding supporting evidence was also found in Siegling, Saklofske, Vesely, and Nordstokke (2012) in which males were known to score higher in the intrapersonal domains of well-being and self-control and females tended to score higher in the interpersonal domains of emotionality and sociability based on TEIQue. Contradictory findings from the studies reviewed here, however, could reflect cultural and religion differences in which the study was carried out.

\section{$H_{0}$ 3: There is no relationship between trait emotional intelligence and maths performance among undergraduates.}

Table 5. A Pearson's correlation between trait emotional intelligence and maths performance (grades) of undergraduates.

\begin{tabular}{clcc}
\hline & & $\begin{array}{c}\text { Trait Emotional } \\
\text { Intelligence }\end{array}$ & Grades \\
\hline Trait Emotional & Pearson Correlation & 1 & $.357 * *$ \\
Intelligence & Sig. (2-tailed) & & .000266 \\
Grades & Pearson Correlation & $.357 * *$ & 1 \\
& Sig. (2-tailed) & .000266 & \\
\hline
\end{tabular}

Table 5 shows a significant correlation between trait emotional intelligence $(\mathrm{M}=121.14, \mathrm{SD}=15.75)$ of undergraduates and maths performance $(M=3.490, S D=0.697)$ and it suggested a moderately weak relationship between the variables in which $\mathrm{r}(100)=.357, \mathrm{p}=0.002$.

This result was also supported by Ogundokun and Adeyemo (2010), Mavroveli and Sánchez Ruiz (2011) and Espinosa (2016) which found a positive relationship between trait EI and mathematical achievements. According to Kanhai (2014), there existed a relationship between emotional intelligence and students' maths achievements because the elements of emotional control and management could serve as predictors in maths and science grades. Corresponding to this, both Corno and Rohrkemper (1985), and McLeod (1988) underlined the importance of working memory in mathematics and it worked best in situations where emotions and feelings were well controlled.

In sum, this study shows a significant correlation between traits EI and maths achievements of undergraduates. Thus, the null hypothesis was rejected and this showed that traits EI could be relatively important as a predictor of maths achievements of undergraduates. In line with this, Ogundokun and Adeyemo (2010) argued that trait EI was a potential predictor of mathematics and English language achievements and suggested that academic performance of students could be improved by overcoming teaching-learning obstacles through the integration of trait EI with school curriculum in which teachers, educational and counselling psychologist were encouraged to participate. The encouraging news was that because students would have strong achievement motivation through 
appropriate arrangement of counselling programmes and enabling environments (Ogundokun \& Adeyemo, 2010). In addition, Espinosa (2016) stated that trait EI should be incorporated in the curriculum of students to further boost their maths achievements and developing students' trait EI would lead to higher self-confidence in mathematical abilities. Hence, trait EI is a useful predictor of learning and should be emphasized in lesson teaching because it enables students to enjoy learning Maths in an efficient way (Homayouni, 2011).

\section{CONCLUSION}

As a conclusion, this research has demonstrated that, though relatively modest, trait emotional intelligence and maths achievements among undergraduates are positively correlated. Test results, however, showed no significant differences in terms of undergraduates' demographic attributes on maths performance and trait emotional intelligence (with the exception of gender on maths achievements). In spite of these, the outcome of the study appears to suggest that trait emotional intelligence can help undergraduates to understand themselves more and to control and manage their emotions and feelings and have better relationship with their surroundings. And this could positively impact on their maths achievements.

\section{REFERENCES}

Alkhateeb, H. M. (2010) Gender differences in mathematics achievement among high school students in the United Arab Emirates. School Science and Mathematics, 101(1), 5-9.

Alokan, F. B., \& Arijesuyo, A. E. (2013). Rural and urban differential in student's academic performance among secondary school students in Ondo State, Nigeria. Journal of Educational and Social Research, 3(3), $213-217$.

Aradilla-Herrero, A., Tomás-Sábado, J., \& Gómez-Benito, J. (2013). Associations between emotional intelligence, depression and suicide risk in nursing students. Retrieved from https://www.researchgate.net/publication/252324721_Associations_between_emotional_intelligence_depress ion_and_suicide_risk_in_nursing_students.

Beilock, S.L., \& Maloney, E.A. (2015). Math anxiety: A factor not to be ignored. Policy Insights from the Behavioral and Brain Sciences. 2(1), 4-12. doi: 10.1177/2372732215601438

Bértola, L., Prados, L., \& Williamson, J. G. (2010). Latin American Inequality in the Long run. Journal of lberian and Latin American Economic History, 28(2), 219-226.

Brian M. G., \& Jeffrey J.W. (2012). Emotional self-efficacy moderates anxiety related impairments in math performance in elementary school age youth. Personality and Individual Differences, 52(2), 118-122.

Cha, Christine B., \& Marin K. Nowak. (2009). Emotional intelligence is a protective factor for suicidal behavior. Journal of the American Academy of Child and Adolescent Psychiatry, 48, 422-430.

Corno, L., \& Rohrkemper, M. (1985). The intrinsic motivation to learn in classrooms. In C. Ames, \& R. Ames (Eds.), Research on motivation (pp. 53 - 90). New York: Academic Press.

Corradino, C. \& Fogarty, K. (n.d.). Positive Emotions and Academic Achievement. Retrieved from http://steinhardt.nyu.edu/appsych/opus/issues/2016/spring/corradino_fogarty.

Cummins, D. (2014). The dark side of emotional intelligence. Journal of Personality Assessment, 97(5), 525535.

Durisch, A. B. (n.d.). Education and suicide. Retrieved from http://www.globaleducationmagazine.com/ education-suicide/pill.

Espinosa, A. (2016). Trait emotional intelligence, self-confidence and valuation of mathematics: mediation and moderated mediation analyses of summer versus regular semester students. International Journal of Teaching and Education, 4(2), 23-48.

Essel, G., \& Owusu, P. (2017). Causes of students' stress, its effects on their academic success, and stress management by students. Retrieved from https://www.theseus.fi/bitstream/handle/10024/ 124792/Thesis\%20Document.pdf?sequence=1

Festus, A.B. (2012). The relationship between emotional intelligence and academic achievement of senior secondary school students in the Federal Capital Territory, Abuja. Journal of Education and Practices, 3(10). Retrieved from http://www.iiste.org/Journals/index.php/JEP/article/view/2526.

Gallagher A. M., \& Kaufman, J. C. (2005). Integrative conclusion in gender differences in mathematics: An integrative psychological approach. Cambridge University Press.

Gardner, H. (1983). Frames of mind. New York: Basic Books.

Gerrish, K., \& Lacey, A. (2010). The research process in nursing. Chichester, West Sussex, U.K: WileyBlackwell. 
Goh Yi Wen (2018). (Unpublished). Final Year Project submitted to the Faculty of Cognitive Science and Development.

Homayouni, A. (2011). Comparisonal investigation of emotional intelligence in addicted and nonaddicted people. European Psychiatry 26(1), 53. https://doi.org/10.1016/S0924-9338(11)71764-3.

Ismail, N. A., \& Halimah, A. (2007). Gender differences in mathematics learning in Malaysia. Retrieved from https://www.researchgate.net/publication/268390962_Gender_Differences_in_Mathematics_Learning_in_M alaysia.

Jensen, A. R. (1998). The g factor: The science of mental ability. Westport, Ct.: Praeger.

Jiuan, C.Y. (2009). Interrelationships between students' attitudes toward mathematics, beliefs about mathematics learning, Confidence in solving mathematical problems and mathematics performance. Retrieved from https://ir.unimas.my/6945/.

Kanhai, A. (2014). Emotional intelligence: A review of researches. European Academic Research, 2(1), 797-834. Retrieved from http://euacademic.org/UploadArticle/473.pdf.

Khairiyah, N. A., Ismail, Z., \& Yusof, Y. M. (2016). The relationship between emotional intelligence and mathematical competency among secondary school students. Journal on Mathematics Education, 7(3), 91100. Retrieved from https://www.researchgate.net/publication/310739785_The_ Relationship_between_Emotional_Intelligence_and_Mathematical_Competency_among_Secondary_School Students.

Mavroveli S., \& Sanchez-Ruiz M. J. (2011). Trait emotional intelligence influences on academic achievement and school behaviour. British Journal of Educational Psychology, 81, 112-134.

McLeod, D. B. (1988). Affective issues in mathematical problem solving: Some theoretical considerations. Journal for Research in Mathematics Education, 19, 134-141.

Moakler, M.W., Kim, J., \& Minsun, M. (2014). College major choice in STEM: Revisiting confidence and demographic factors. Career Development Quarterly, 62(2), 128-142.

Mohamed, L., \& Waheed, H. (2011). Secondary students' attitude towards mathematics in a selected school of Maldives. $\quad$ Retrieved from https://www.researchgate.net/profile/Hussain_Waheed/ publication/266009828_Secondary_Students'Attitude_towards_Mathematics_in_a_Selected_School_of_Mal dives/links/584fa72008aecb6bd8d1d6a4/Secondary-Students-Attitude-towards-Mathematics-in-a-SelectedSchool-of-Maldives.pdf.

Ogundokun, M. O., \& Adeyemo, D. A. (2010). Emotional intelligence and academic achievement: The moderating influence of age, intrinsic and extrinsic motivation. The African Symposium: An Online Journal of the African Educational Research Network 10(2): 127-141.

Petrides, K. V. (2009). Psychometric properties of the Trait Emotional Intelligence Questionnaire (TEIQue). In C. Stough et al. (Eds.), Assessing Emotional Intelligence. The Springer Series on Human Exceptionality. doi 10.1007/978-0-387-88370-0_5.

Petrides, K. V. (2011). Ability and Trait Emotional Intelligence. The Wiley-Blackwell Handbook of Individual Differences, First Edition., pp 657-678. Retrieved from https://pdfs.semanticscholar.org/96c8/ 9c4a38c6118dd62486817da6dab8ef8d520e.pdf.

Petrides, K. V., Frederickson, N., \& Furnham, A. (2004). The role of trait emotional intelligence in academic performance and deviant behavior at school. Personality and Individual Differences, 36, $277-293$.

Pillay, S. (2017). Suicide on the rise among Malaysian youth. Retrieved from https://www.nst.com.my/news/exclusive/2017/05/243354/suicide-rise-among-malaysian-youthkhai.

Ratnawati, M. F., \& Ismail, S. A. (2003). Promoting english language development and the reading habit among students in rural schools through the guided extensive reading program. Reading in a Foreign Language, 15(2), 83-102.

Siegling A. B., Saklofske D. H., Vesely A. K., \& Nordstokke D. W. (2012). Relations of emotional intelligence with gender-linked personality: Implications for a refinement of EI constructs. Personality and Individual Differences, 52, 776-781.

Siegling, A.B., Furnham, A., \& Petrides, K. V. (2015). Trait Emotional Intelligence and Personality: GenderInvariant Linkages Across Different Measures of the Big Five. Journal of psychoeducational assessment, 33 (1), 57-67.

Siegling, A.B., Vesely, A.K., Petrides, K.V., \& Saklofske, D.H. (2015) Incremental validity of the trait emotional intelligence questionnaire-short form (TEIQue-SF). J Pers Assess, 97(5), 525-35.

Sindermann, C., Kendrick, K. M., Becker, B., Li, M., Li, S., \& Montag, C. (2017). Does growing up in urban compared to rural areas shape primary emotional traits?Behavioral Sciences, 7(3), 60. http://doi.org/10.3390/bs7030060.

Stankov, L., Lee, J., Luo, W., \& Hogan, D. J. (2012). Confidence: A better predictor of academic achievement than self-efficacy, self-concept and anxiety? Learning and Individual Differences, 22, 747-758. 
Wahid, S. N. S., Yusof, Y., \& Razak, M. R. (2014). Math Anxiety among Students in Higher Education Level. Retrieved from https: //www.researchgate.net/publication/ 273851358_Math_Anxiety_among_Students_in_ Higher_Education_Level.

Waldman, N. (2012). How can a teacher best motivate parents to become more involved in their child's academic development? Retrieved from https://www.quora.com/How-can-a-teacher-best-motivate-parents-to-becomemore-involved-in-their-childs-academic-development.

Whitfield, L. (2012). How countries become rich and reduce poverty: A review of heterodox explanations of economic development. Development Policy Review, 30(3), 239-260.

Wile, E. (2017). Why is math so important for kids to learn? Retrieved from https://www.livestrong.com/article/255620-why-is-math-so-important-for-kids/

Wilkins, J.L., \& Ma, X. (2002). Predicting student growth in mathematical content knowledge. Retrieved from http://www.soe.vt.edu/tandl/pdf/Wilkins/Publications_Wilkins_Predicting_student_growth_in_mathematical _content_knowledge.pdf.

$\mathrm{Wu}, \mathrm{H}$. P., Garza, E., \& Guzman, N. (2015). International student's challenge and adjustment to college. Retrieved from https://www.hindawi.com/journals/edri/2015/202753/cta/. 